\title{
Microwave Ablation Aided Surgery for Benign Aggressive Bone Tumors in the Extremities: Technical Points
}

\section{Miaomiao Liang}

China Medical University First Hospital

Yu Chen ( $\nabla$ toeflmugou@163.com )

China Medical University First Hospital https://orcid.org/0000-0002-6657-3237

\section{Research article}

Keywords: Microwaves, ablation techniques, bone neoplasms, curettage, blood loss

Posted Date: February 17th, 2020

DOI: https://doi.org/10.21203/rs.2.23712/v1

License: (c) (1) This work is licensed under a Creative Commons Attribution 4.0 International License.

Read Full License 


\section{Abstract}

The authors have requested that this preprint be removed from Research Square. 